University of New Hampshire

University of New Hampshire Scholars' Repository

$1-11-2016$

\title{
Elementary Preservice Teachers as Warm Demanders in an African American School
}

\author{
Elyse Hambacher \\ University of New Hampshire, elyse.hambacher@unh.edu \\ Melanie M. Acosta \\ University of Alabama \\ Elizabeth Bondy \\ University of Florida \\ Dorene D. Ross \\ University of Florida
}

Follow this and additional works at: https://scholars.unh.edu/educ_facpub

Part of the Education Commons

\section{Comments}

This is an Author's Original Manuscript. The final publication is available at Springer via http://dx.doi.org/10.1007/

s11256-016-0350-4

\section{Recommended Citation}

Hambacher, E., Acosta, M., Bondy, E., \& Ross, D. D. (2016). Elementary preservice teachers as warm demanders in an African American school. The Urban Review, 42(2), 175-197.

This Article is brought to you for free and open access by the Education at University of New Hampshire Scholars' Repository. It has been accepted for inclusion in Education Scholarship by an authorized administrator of University of New Hampshire Scholars' Repository. For more information, please contact Scholarly.Communication@unh.edu. 
ELEMENTARY PRESERVICE TEACHERS AS WARM DEMANDERS

\section{ELEMENTARY PRESERVICE TEACHERS AS WARM DEMANDERS IN AN}

\section{AFRICAN AMERICAN SCHOOL}

Preparing and retaining high quality teachers is one of the most pressing aspects of achieving educational equity, particularly in urban schools serving large numbers of African American students (Darling-Hammond, 2010; Hunter, 2012; Sunderman \& Kim, 2005). Researchers have consistently documented the significant impact effective classroom teachers have on African American student achievement, yet literature on teacher preparation specifically for African American children is limited (Ladson-Billings, 1994, Milner, 2009; Moore \& Lewis, 2012). While some studies do focus on African American learners, they often emerge from a deficit paradigm where the words "at-risk" and "culturally deprived" are used to depict African American students and their communities as a set of pathological conditions for which teachers must be prepared to compensate (Bettleheim, 1965; Ornstein \& Viaro, 1968; Payne, 2005). Practices such as tracking students into special education (Hart, Cramer, Harry, Klingner, \& Sturges, 2010), low teacher expectations (Boser, Wilhelm, \& Hanna, 2014; Diamond, Randolph, \& Spillane, 2004; Palmer, 2010) and exclusionary discipline (Gregory, Skiba, \& Noguera, 2010) are undergirded by deficit-based perspectives and have become pervasive in urban classrooms. These perspectives often obscure teachers' vision and enactment of effective instruction for African American learners. Therefore there is great need for teachers to enter the profession better prepared with the conceptual and practical tools to resist ideas and approaches harmful to student learning, and instead teach African American children for educational excellence.

In response, some scholars have begun to advance the knowledge base on teacher preparation for African American students (e.g. Hilliard, 2014; Milner, 2009; Milner \& Tenore, 2010; Moore \& Lewis, 2012). These studies represent a critical departure from deficit-based This is an Author's Original Manuscript. The final publication is available at Springer via http://dx.doi.org/10.1007/s11256-016-0350-4 


\section{ELEMENTARY PRESERVICE TEACHERS AS WARM DEMANDERS}

research, focusing on the practices of exemplary teachers who work to improve the lives of African American children and their communities. Emerging from such scholarship is the concept of the teacher as "warm demander"- - teachers who espouse values and embrace practices central to their students' achievement (Authors, 2007, 2013; Irvine \& Fraser, 1998; Ware, 2006). Research on the dispositions and practices of warm demanders in African American educational contexts highlights the potential of this approach to counter the pernicious trends in African American education.

To date, no studies examine warm demanding in the context of preservice teacher education. In this study, we use qualitative methods to understand how two female preservice teachers (PSTs) in a full-time internship conceptualize and work to become warm demanders for their African American students. Our study was guided by the overarching question, "How do elementary preservice teachers make sense of warm demanding?" Our study is important because it extends the research on effective pedagogy for African American learners to include ways to explicitly support prospective teachers in their development of culturally relevant teaching.

\section{Literature Review}

Ladson-Billings (1994) describes culturally relevant teaching for Black students as a pedagogy that "empowers students intellectually, socially, emotionally, and politically by using cultural referents to impart knowledge, skills, and attitudes" (pp. 17-18). Premised upon a deep valuing of, and respect for students' culture and background, culturally relevant teaching advocates teaching the whole-child; it includes instruction that cultivates children's academic, social, emotional, political, and ethical development. We situate warm demanding within this culturally relevant pedagogical framework because warm demanding deepens the literature on This is an Author's Original Manuscript. The final publication is available at Springer via http://dx.doi.org/10.1007/s11256-016-0350-4 


\section{ELEMENTARY PRESERVICE TEACHERS AS WARM DEMANDERS}

effective instructional approaches for African American children by explicating two pedagogical dispositions central to culturally relevant teachers' powerful instructional approach: care and authority. More specifically, the literature on warm demanding provides a nuanced understanding of the nature of care and authority as they relate to teaching children of color well.

We conceptualize warm demanding as a stance to teaching grounded in a social justice commitment to improve the lives of Black children (Authors, 2013). Guided by the confluence of teacher care and authority, warm demanders provide "a tough-minded, no-nonsense, structured, and disciplined classroom environment for kids whom society has psychologically and physically abandoned" (Irvine \& Fraser, 1998, p. 56). Teachers who embody this stance exhibit an "active demandingness" which is not a central characteristic in the dominant literature on effective teaching (Kleinfeld, 1975). However, the warm demander skillfully balances both care and authority to create a task-oriented learning environment that supports a culture of achievement for Black students (Authors, 2008). A small but growing literature base documents the perspectives and practices of the warm demander.

Ware's (2006) seminal work outlined the beliefs and practices of warm demanders in a qualitative study of two experienced African American teachers. The teachers taught in dissimilar contexts - one was a 30-year veteran elementary school teacher in the lowest income community in the district and the other taught for six years in a middle school that included lowand middle-income predominately Black students. Using semi-structured interview and observation data, Ware's study found that the teachers' no-nonsense approach typified the warm demander stance as they were quick to curtail inappropriate behavior when students were not meeting teachers' expectations. While this assertive style may be perceived by some observers as "harsh," many teachers and students within the Black community perceive a no-nonsense This is an Author's Original Manuscript. The final publication is available at Springer via http://dx.doi.org/10.1007/s11256-016-0350-4 


\section{ELEMENTARY PRESERVICE TEACHERS AS WARM DEMANDERS}

approach as demonstration of teachers' belief in their students' ability to succeed; indeed, it is understood as evidence of teachers' care and concern for students' wellbeing (Corbett, Wilson, \& Williams, 2002). In other words, when one listens closely, warm demanders' assertiveness is not intended to control students. Instead, warm demanders communicate care for students through unrelenting insistence on high-quality performance.

Insistence is a key feature of the warm demander (Authors, 2008). Warm demanders insist because they wholeheartedly adopt the belief that children can and must learn, and that it is the teacher's responsibility to teach them (Corbett et al., 2002). The key to the power of insistence is the relationship building that the teachers have conducted with students. Because they have developed personal relationships, students understand that the teacher has their best interests in mind. In practice, warm demanders insist by reminding and reinforcing their expectations, and by holding students accountable. Warm demanders instruct with authority and ground their teaching practices in a culture of mutual respect that they co-construct with students; that is, a teacher's authority is not assumed (Delpit, 1995). Because their classrooms are grounded in mutual respect, the tone of insistence is firm, yet warm; business-like, but caring. The authoritative warm demander is not to be confused with the authoritarian teacher, who imposes rigid restrictions, teaches them to be complacent rather than engaged, and is often feared. Being insistent means the classroom is guided by proactive strategies to teach expectations in conjunction with an abiding support for students to meet these expectations (Authors, 2008).

In a grounded theory case study, Bonner and Adams (2012) explored one veteran African American warm demander in the context of mathematics instruction. Using semi-structured interviews and observations over a four-month period, Bonner and Adams found that fifth-grade teacher gained extensive knowledge of her students and the community in which they lived. She This is an Author's Original Manuscript. The final publication is available at Springer via http://dx.doi.org/10.1007/s11256-016-0350-4 


\section{ELEMENTARY PRESERVICE TEACHERS AS WARM DEMANDERS}

often walked in the community neighborhood after school, visiting students and their families which she believed was important in strengthening her relationships with them. The knowledge she gained of students and their families allowed her to teach math content in ways that were relevant and exciting to students. This warm demander communicated in culturally relevant ways and was not afraid to display a firm tone to express her displeasure when students did not try their best. Consistent with other research on warm demanding, her insistence grew out of her understanding that society perceives African Americans from a deficit paradigm; thus, she viewed it as a moral imperative to empower students to defy the stereotypes of African American people.

While some research portrays warm demanders as older, experienced, Black teachers, scholars have begun to examine warm demanding within the context of novice, non-Black teachers. For instance, Authors (2013) interviewed and videotaped two first-year White teachers who worked to become warm demanders, both of whom were graduates of an internship program designed to prepare prospective teachers to teach in high-poverty elementary schools. The findings highlight a contrast between two novices, one who viewed warm demanding as a stance for teaching, and one who viewed the concept as a set of strategies for classroom management. Even though both teachers talked about caring as critical for student-teacher relationships, the former teacher talked extensively about caring as connectedness to her students and their families whereas the latter teacher spoke about caring in terms of her words and actions. That is, it was important to the first teacher that students perceive her actions as caring. In contrast, the second novice focused solely on her caring intentions rather than how students perceived her care. She interpreted care from a Eurocentric perspective, one that did not consider her students' cultural constructions of care, which at times led her to struggle with student This is an Author's Original Manuscript. The final publication is available at Springer via http://dx.doi.org/10.1007/s11256-016-0350-4 


\section{ELEMENTARY PRESERVICE TEACHERS AS WARM DEMANDERS}

cooperation. This study revealed that if teachers are to communicate abiding care for their students, it is crucial for care to be recognized and felt by the students. Demonstrations of teacher care are crucial for Black children given the priority of person-to-person relationships and interpersonal intelligence within Black culture (Boykin, 1994; Nobles, 1985).

Warm demanders instruct with authority and demonstrate interpersonal caring by which care is associated with creating an environment where "support and encouragement are primary characteristics and where teachers and students interact in personal, familial ways" (Siddle Walker, 1993, p. 65). At its essence, warm demanding is characterized by an abiding care manifested through pedagogical decisions where assuming responsibility for students' wellbeing is at the center of practice.

\section{Positioning Ourselves as Researchers in the African American Community}

Tillman (2002) posits that researchers do not have to share the same racial or cultural background as their participants; however, they must be culturally sensitive, thoughtful, and transparent when conducting research related to issues of race and culture. As two White researchers, one African American researcher, and one biracial researcher (Asian and White), we agree that racism is endemic to the American experience, and subsequently shapes the experiences of all individuals. This critical ideology emerges from our various experiences with African American children, teachers, administrators, and community members. We each have spent considerable time in African American school settings and have been privy to the impact warm demanders have on student success. We have also witnessed the dire consequences for African American students who do not have warm demanding teachers. We believe that warm demanders are necessary for high academic achievement, but more importantly, are crucial for transforming schools into beacons of democracy and equity. This is an Author's Original Manuscript. The final publication is available at Springer via http://dx.doi.org/10.1007/s11256-016-0350-4 


\section{ELEMENTARY PRESERVICE TEACHERS AS WARM DEMANDERS}

\section{Methodology}

The qualitative study was designed to address a typical, qualitative question: "How do two preservice teachers in a full-time internship in a predominately African American elementary school make sense of warm demanding?" We were particularly interested in gaining insight into the PSTs' understanding of warm demanding and their assessment of themselves as warm demanders. Given the constructivist nature of the question, we collected interview, online discussion, and video data. All four researchers analyzed the data using an inductive analysis strategy (Hatch, 2002). The following sections describe the context in which these PSTs learned about and enacted warm demanding, the process for participant selection, data collection, and data analysis strategies.

\section{Context}

The two preservice teacher (PSTs) participants completed internships in a predominately African American and low-income (75\% African American; 88\% free/reduced lunch) elementary school. Concurrent with the internship, the PSTs were enrolled in a three-credit hour blended course (online and face-to-face) designed to scaffold their success in learning to teach in highpoverty, predominately African American schools by helping PSTs develop perspectives and skills demonstrated by effective teachers of diverse populations of children living in poverty (Corbett et al., 2002; Ladson-Billings, 1994). The course focused explicitly on developing knowledge about African American culture; examining the predominantly White PSTs' assumptions about students and families represented in their classrooms; and developing a stance of care, high expectations, insistence, and teacher responsibility for student learning, characterized in the literature as warm demanding (Authors, 2007; Ware, 2006).

The course encouraged PSTs to develop and experiment with practical tools associated This is an Author's Original Manuscript. The final publication is available at Springer via http://dx.doi.org/10.1007/s11256-016-0350-4 
with warm demanding, such as: establishing a strong ethos of care and respect that undergirds instruction and classroom interaction; communicating high expectations for student performance; developing an authoritative stance that ensures student effort and excellence; and providing instruction that is culturally familiar, sensitive to student difference, explicit, and focused on mastery. Course pedagogy involved the following strategies and assignments.

\section{Opportunity to gain knowledge about African American culture. The African} American principal of the participants' school invited the PSTs to join her at an African American church service within the school attendance zone and attended by many school families. All PSTs attended and reflected on the cultural assets they observed. They linked their observations to attributes of African American culture as synthesized by this principal (Moss, 2010) from sources such as Allen and Butler (1996) and Boykin, Tyler, and Miller (2005) and wrote reflective journal entries about how they might draw on attributes observed in the church service to enhance their connections to and effectiveness with their students. Ongoing opportunities to talk with the school's principal about their observations, experiences and readings were deliberate attempts to develop PSTs' knowledge of children they were teaching.

Develop clear images of culturally relevant practice. In addition to reading descriptions of effective pedagogy, PSTs viewed and analyzed two video exemplars - Good Morning Miss Toliver (Heard et al., 2010), and a video of culturally relevant classroom management practices from two schools in the same community with the same school demographic characteristics (Authors, 2007). Additionally, each PST observed two accomplished teachers in local schools to help students "see" culturally relevant pedagogy in the practice of local mentor teachers. 
ELEMENTARY PRESERVICE TEACHERS AS WARM DEMANDERS

Scaffolded development of practical tools. To ensure that the PSTs connected their conceptual learning to their practice, they were required to implement culturally relevant teaching strategies identified from the literature. They were required to develop a child study notebook to document their knowledge of each student's community, personal, and school related assets, and to document interactions with children's families. Additionally, they were regularly required to try strategies and reflect on their impact in an online course forum and to conduct formal inquiries such as a lesson study project.

\section{Participants}

The two participants were invited based on their instructor's nomination as skilled, knowledgeable, and dedicated novices who demonstrated commitment to the success of African American students. That is, for this study we sought PSTs who were actively working to become warm demanders in order to examine their successes and challenges. The two PSTs, both female and 22 years old, included Katelyn (kindergarten) and Maya (second grade). Katelyn identified as White and Maya as Latina. Both agreed to participate in the study. Although the course instructor is one of the authors on the manuscript, she did not know who agreed to participate in the study, was not the lead researcher, and the students understood that no data would be analyzed until after grades for the semester had been submitted.

\section{Data Collection}

Primary data sources included two 60-minute interviews with each PST and online discussion posts made during the 16-week blended course. Interviews followed classroom observations (described below) with the goal of exploring the PSTs' constructions of warm demanding. In the online forum, PSTs described and reflected upon the principles of warm demanding they believed they implemented in their classrooms. They also responded to the This is an Author's Original Manuscript. The final publication is available at Springer via http://dx.doi.org/10.1007/s11256-016-0350-4 


\section{ELEMENTARY PRESERVICE TEACHERS AS WARM DEMANDERS}

descriptions and reflections of their peers, resulting in lengthy discussions of practices and their outcomes.

As a secondary source, the first author recorded two 30-minute videos of classroom teaching for each PST. Videos were recorded digitally and shared with the relevant PST. The videos were not analyzed in great detail; rather, they served as a tool to elicit PSTs' understandings about warm demanding. The researchers' purpose was to situate the PSTs' description of warm demanding within the particulars of specific lessons and students. Hence, the conversational interviews focused on questions such as, "I noticed that you ..." and "Tell me about that moment in the lesson. Is there evidence of warm demanding in action?" Interviews were recorded and transcribed verbatim.

\section{Data Analysis}

Four researchers collaboratively analyzed the data. The two junior researchers led the analysis, one assigned to each PST. The two senior researchers served as consultants throughout the research process. Using an inductive and recursive approach (Hatch, 2002), we examined the data with the following questions in mind: (1) What is the PST's understanding of warm demanding? (2) How does the PST assess her enactment of warm demanding?

In order to understand the PST's perspectives, we attended closely to the ways in which the participants described and explained their views and their practices in the interviews and online discussion groups. An inductive analysis was chosen because it begins with the specifics of participants' words and moves to "looking for patterns across individual [words], then arguing for those patterns as having the status of general explanatory statements" (Potter, 1996, p. 151). Data were systematically analyzed using a series of steps. First we read each PSTs data set to generate a list of possible codes or domains that captured the PST's emerging understanding of This is an Author's Original Manuscript. The final publication is available at Springer via http://dx.doi.org/10.1007/s11256-016-0350-4 


\section{ELEMENTARY PRESERVICE TEACHERS AS WARM DEMANDERS}

and efforts to enact her understanding of warm demanding. This process of domain analysis (Spradley, 1980) is intended to "develop a set of categories of meaning...that reflects

relationships represented in the data" (Hatch, 2002, p. 104). Spradley's (1980) domain analysis is useful because it prompts the researcher to identify "ways to do things," "reasons for things," "steps in a process," and similar categories of participants' reality as represented in the data.

Next, the four researchers discussed and developed shared definitions of the generated domains. For example, "ways to build relationships" represented the ways in which a PST cultivated relationships with children and families. Similarly, "reasons for warm demanding" represented the PST's thinking about the importance of warm demanding, and "kinds of concerns about my warm demanding" represented the PST's doubts about her enactment of warm demanding. In an effort to clarify each PST's understandings and practices, the team revisited the data and the domains individually and collectively to ensure consistency in interpretation of data and assignment of data to domains. The collaborative, recursive process of data analysis, discussion, and further analysis continued as we sought confirming and disconfirming evidence of themes in the data.

Then, the research team paired up to write two initial memos that captured each PST's understanding and enactment of warm demanding. Discussion of these initial memos challenged the researchers to revisit the discussions of warm demanding in the literature in order to make sense of similarities and differences between the PSTs. Specifically, although the videos indicated stark differences in their practice, the interviews and discussion posts along with the warm demanding literature helped us to recognize that the two PSTs represented "variations on the theme" of warm demanding. Following discussion of initial memos, the junior researchers rewrote their initial memos as case studies and the team met to refine the cases. This is an Author's Original Manuscript. The final publication is available at Springer via http://dx.doi.org/10.1007/s11256-016-0350-4 


\section{ELEMENTARY PRESERVICE TEACHERS AS WARM DEMANDERS}

\section{Findings}

Drawing from Ware's (2006) framework of the warm demander as caregiver and authority figure, the cases of Katelyn and Maya convey variations on the thematic commitments to embracing warm demanding as a stance. We use the term stance to designate the psychological and ideological influences on teacher perspectives and practices. In earlier work, Authors (2013) noted that warm demanding is more than a set of strategies used to ensure student success. Warm demanding also requires a particular theoretical stance, or disposition towards teaching, children, and community. Although the current study was not designed to study the impact of warm demanding on student achievement, the two cases provide insight into the ways in which the PSTs made sense of and attempted to enact warm demanding with their African American students.

\section{Katelyn: The Warm Demander as Caregiver}

Katelyn's over-arching goal was to work toward establishing a learning environment grounded in a culture of success and mutual respect, where "mistakes are okay" and students felt safe to take risks (KI2). She conceptualized a warm demander as a teacher who:

sets very high expectations for students and does not accept less ... but goes about getting them in a way that is very respectful of the students and does not undermine them as people ... but lets them know ... that this is the expectation. (KI2)

Caring for students meant that she was responsible for creating a positive learning community with respect at the core. She viewed respect as having a high regard for students, treating others well, and encouraging students to support the successes of peers. She believed that it was her duty to show students how to participate in the learning environment: 


\section{ELEMENTARY PRESERVICE TEACHERS AS WARM DEMANDERS}

I don't think maximum learning can occur if you don't have a strong positive classroom community, and I think the teacher is the facilitator in that. Being a warm demander is the first step in setting the example ... for this is how we are going to treat each other in this classroom. (KI1)

One way Katelyn worked to establish and maintain a caring and respectful learning community was through a Bucket Filling activity (McCloud, 2006) in which students' buckets are filled when they say or do something kind (e.g. showing respect to others, helping without being asked). For example, when one student began to cry because another student refused to sit next to him, Katelyn responded, 'Everyone, we have a friend who is feeling sad. Why don't we fill his bucket by saying something we like about him" (KDF101909)? This activity encouraged students to treat each other well and reinforced Katelyn's commitment to maintaining a respectful classroom environment.

Katelyn believed this kind of community was needed to facilitate student success, and demonstrate her unrelenting care for students. She elaborated on the connection between care and her teaching practice:

You have to genuinely care about the kids you work with.... if this concern is genuine, it would be impossible to turn it off at 1:45. I am constantly thinking about my students ... and brainstorming more effective ways to reach them. In some ways, ... my

most valuable contributions to my students occur outside school hours. (KDF110809)

Katelyn believed it was crucial to build genuine relationships with students at the beginning of the year. Drawing on an idea from the course, she took photographs of each student and completed a Hopes and Dreams activity (Charney, 2002) that gave insight into the children's individual interests and aspirations. She shared her own hope to "help young children learn" and This is an Author's Original Manuscript. The final publication is available at Springer via http://dx.doi.org/10.1007/s11256-016-0350-4 


\section{ELEMENTARY PRESERVICE TEACHERS AS WARM DEMANDERS}

expressed excitement to "try out some of [her] ideas . . . to help each one of them learn something new and exciting" (KDF082609). Together, they discussed some of the things she hoped for them and goals they wanted to reach for themselves.

Katelyn also got to know students' interests and cultural backgrounds by taking advantage of opportunities to learn about their community. As part of a course requirement, she participated in the school's fall festival and a church service that immersed her into the African American community. After attending the African American church service she said:

There was a very powerful sense of communal understanding and bonding. . . . All [church] members seemed to genuinely care about the well being of their neighbors. They supported one another as they expressed their spirituality.... [They] looked out for the interest of the community over the interest of the individual. (KDF091609)

Although required, it is important to highlight Katelyn's wholehearted commitment to refining her practice from the church experience. As she reflected on the experience, she resolved to try harder to incorporate music and movement into lessons. Her observations led her to conclude that this could bolster students' learning by drawing on cultural assets to demonstrate what they knew. Her observation of the pastor as "very down to earth and straightforward" suggested to her that she must strive to make "content relatable for students and present it in ways they can connect with" (KDF092009).

Her observations cued her to use call-and-response, a kind of "spontaneous verbal and non-verbal interaction between speaker and listener in which all of the statements ('calls') are punctuated by expressions ('responses') from the listener'" (Smitherman, 1977, p. 104). In an interview, Katelyn explained that she drew on her cultural knowledge of the African American 


\section{ELEMENTARY PRESERVICE TEACHERS AS WARM DEMANDERS}

community as well as students' interests to help students identify words with their beginning sounds by creating several interactive call-and-response raps.

Katelyn communicated her abiding care by developing relationships with students for the purposes of teaching responsively. Responsiveness in her planning was evident in the example above and in her first interview as she discussed the genesis of her idea to use rap:

Then I heard some of my students singing a popular rap song. . . . The melody just got stuck in my head ... so what if I could turn that into something educational? So I . . . came up with the letter T-rap. We introduced that rap this week and the students loved it.

I overheard them singing it in centers and after school. I started using it as an incentive because they were asking me, "Can we do the letter T-rap?!” (KI1)

Katelyn tuned into her students in order to plan engaging instruction with a variety of ways for students to participate and learned about students through both formal "getting to know you activities" and through informal observations. Katelyn's care was manifested through the relationships she cultivated with students and her commitment to learning about the communities in which they live.

Katelyn's belief that students are capable of success permeated the classroom culture. Referring to their memorization of song lyrics she asserted, "If they can master this information, they are clearly capable of learning the classroom curriculum" (KDF102109). Katelyn perceived that it was her responsibility to motivate them, and she described a variety of ways to communicate her belief in students' capacity to succeed. These included high-fives (e.g., "I knew you could do it, high-five!") and cheering for them to recognize good performance. She frequently communicated positive, encouraging messages to the class as a whole. In discussing her responsibility to motivate students, she referred to part of her second video: This is an Author's Original Manuscript. The final publication is available at Springer via http://dx.doi.org/10.1007/s11256-016-0350-4 
ELEMENTARY PRESERVICE TEACHERS AS WARM DEMANDERS

Katelyn: Everybody pat yourselves on the back. (Katelyn models this by patting her own back.) Kiss your brain!

Students: (Students pat themselves on their backs, kiss their hands, and touch their heads while exclaiming in unison) I love you, brain! (KV2)

Katelyn explained that motivating students and building their confidence was key to their success, an important commitment for her. The following quote represents her dedication to bolstering student learning:

Some kids are going to pick up on things regardless of whether you do a good or terrible job at teaching it. Is that anything to be proud of? The real prize is reaching those who DON'T pick it up right away. ... I'm proud of my excelling students. . . I'm considerably more proud of the albeit smaller gains of our struggling students. It is with them that I can truly measure the quality of my instruction. (KDF102109)

Katelyn believed that student motivation was the key to learning and understood student motivation to be her responsibility. She explained, "If I look out during a lesson and see that my kids are bored, my first thought is going to be, 'Well, I guess this is a boring activity"' (KDF102109). This statement suggests that Katelyn embraced and enacted a "no excuses" stance to teaching in which she took responsibility for engaging students to ensure their success (Corbett et al., 2002).

As an additional expression of her unwavering commitment to their success, Katelyn worked to establish a community of kindergarteners who encouraged the communal success of their peers. She talked about the importance of helping students to believe that they and their peers were capable, intelligent human beings. She pointed to specific incidents in the video to explain how she tried to achieve this goal. After a student hesitated to participate, she smiled and This is an Author's Original Manuscript. The final publication is available at Springer via http://dx.doi.org/10.1007/s11256-016-0350-4 
insistently responded, "Yes, you can. Come up and try for me" (KV1). When a student experienced difficulty completing a task, several peers encouragingly shouted, "You go boy, you can do it" (KV2)! After the student completed the task successfully, Katelyn and his classmates clapped, provided additional encouraging remarks, and gave the student high-fives to celebrate. In her effort to become a warm demander, she strove to create an environment where students felt comfortable to take risks in learning and encouraged success of the group.

\section{Katelyn: The Warm Demander as Authority Figure}

Katelyn's belief that "there is no room for failure" (KI2) helps explain her instructional urgency. She refused to settle for less than students' best performance because "If you don't set high expectations for your students, you are not going to get high results. If you settle for less, then that's all you're going to get" (KI2). Demanding that students meet her high expectations also meant that she was committed to facilitating their success. From Katelyn's perspective, insisting that students meet her expectations reinforced her message that students are able to succeed. Her authoritative stance was marked by demanding students' best without demeaning them. That is, she was conscious about how she demanded students' best, suggesting that making them feel "stupid" would undercut her efforts and make students "lose confidence in themselves" (KI2). She explained,

If you ... demand those expectations in a way that creates a hostile environment where kids feel scared about making mistakes or they feel like you make them feel stupid or ... like they're not doing a good job, then you're going to defeat your own purpose because they're not going to want to try, [or] want to meet your expectations. (KI2)

She also believed that students must be persistent in meeting her expectations: 


\section{ELEMENTARY PRESERVICE TEACHERS AS WARM DEMANDERS}

I'm not gonna tell them "This is terrible, what were you thinking? This is awful." I'm gonna be like okay you can do better than this ... and I'll give them specific examples. . I'm not going to accept low quality work but I'm also not going to belittle them. . . Just in a kind way, "You can do better than this, this is what I would like you to do, now go back and redo it." (KI2)

Since Katelyn expected that students try their hardest to meet her expectations, she believed that her expectations needed to be repeated throughout the year. She elaborated,

You have to repeat yourself and remind them every single day of what the expectations are. It's not something [where] you can say the rules in August and expect them to remember every single time before we come in the door. I have to say "You need to walk in quietly and go to your spot on the floor" because if you don't, they won't do it. (KI2)

While Katelyn insisted that students meet her expectations, she also noted the significance of being consistent in redirecting behavior in a way that minimized the loss of instructional time. Because academic success was a priority, she did not want to spend too much time "harping on" students who were not meeting her expectations as she felt this could make matters worse: "The less attention you give to the redirection the better, because ... [if] you take the time to stop what you're doing to deal with their misbehavior, there's a very good chance you'll end up with another one (KI2)."

To maintain the instructional pace, Katelyn used quick verbal and non-verbal cues to demand that students meet her expectations. She explained that such cues included counting down from ten, giving verbal directives (e.g., "Robert, I need to see you up, sweetheart"), eye contact, and shaking her head. While Katelyn worked to become a warm demander she admitted to struggles related to consistency.

This is an Author's Original Manuscript. The final publication is available at Springer via http://dx.doi.org/10.1007/s11256-016-0350-4 


\section{ELEMENTARY PRESERVICE TEACHERS AS WARM DEMANDERS}

Katelyn disclosed that becoming a warm demander was harder than she thought it would be. While she embraced the warm demander stance, she admitted, "At the height of the day when you've got six kids trying to get your attention and you've asked something five times, and they still haven't done it ... it's harder to keep your calm, it's harder to be consistent" (KI2). In particular, she found it challenging to find a balance between demanding students' best and not compromising on the respectful, safe learning environment she worked so hard to create. Katelyn said she was "stern and strict;" however, she did not feel that she was ever "downright mean" to students (KI2). The challenge for her was communicating clear, firm expectations without conveying harshness that might undermine the relationship. In an interview, she discussed this dilemma: "It's a struggle because you want to demand from them the best, but you can't go about it in a way that makes them feel bad, that hurts their feelings, that makes them feel . . just not good about themselves" (KI2).

Katelyn admitted to being less consistent at the beginning of the year because she had never worked with such young children and did not want to demand more than was developmentally appropriate. However, as she developed a more personal relationship with students, she was able to be more consistent and insistent. However, at times, Katelyn noted she simply did not know what to do. This is not surprising as many novice teachers find themselves in situations where they are unsure how to respond. Despite strategies learned in the course she asserted, “I'm pointing out the positives, I'm using eye contact and the non-verbal cues, I'm counting down from ten, I'm doing everything right, everything that worked yesterday. But it's not working right now, so what do I do" (KI2)? Each day was filled with new skills to learn and when students lost focus, she believed that she struggled to stay calm. She worried that students might see her become frustrated, and she did not want to send them a negative message. This is an Author's Original Manuscript. The final publication is available at Springer via http://dx.doi.org/10.1007/s11256-016-0350-4 


\section{ELEMENTARY PRESERVICE TEACHERS AS WARM DEMANDERS}

In summary, Katelyn's expression of warm demanding was grounded in a learning environment characterized by a culture of success and mutual respect. She conveyed care for her kindergarteners by establishing genuine relationships and using cultural knowledge gleaned from community experiences to motivate and make learning culturally relevant. Holding herself responsible for their academic success, she insisted that students work diligently to meet her high expectations. Despite some challenges, her understanding and enactment of warm demanding showed that she was deeply committed to her students and their success.

\section{Maya: The Warm Demander as Caregiver}

Similarly, Maya's belief in the classroom as a comfortable learning community was one way she embraced the warm demander stance. She believed in connecting with students personally, and viewed this connectedness as a critical factor in teaching them well. She shared:

Getting to know [students] on a personal level and understanding how each student works ... you don't have to do that, but when you do that as a teacher you're able to connect with students because ... you're on the level of understanding how they function, what they like, how they learn so you know how to approach them. (MI1)

Having a strong belief in a connected, classroom community led Maya to work to build and maintain positive relationships with students and families. Making students feel comfortable was one way Maya conveyed that she was genuinely invested in their success. She established an emotional connectedness with students by engaging in conversations, laughing and joking, and placing herself close to them. More importantly, she demonstrated an understanding of how such measures positively influenced her teaching and the academic success of her predominantly African American students. In her second interview, she stated, "We try to make jokes so we laugh together ... and because we've gotten to know each other and we've had the opportunity This is an Author's Original Manuscript. The final publication is available at Springer via http://dx.doi.org/10.1007/s11256-016-0350-4 
ELEMENTARY PRESERVICE TEACHERS AS WARM DEMANDERS

to structure our classroom ... we've been able to function as a group without me having to stop every two seconds" (MI2).

In the course she took during her internship, she shared that smiling, showing interest in her students' lives outside the classroom, and humor are ways that she "connects with students on a personal level which enhances the academic level that [she and her students] connect at" (MDF112309). Maya demonstrated care in other ways as well. Observations of her practice showed that she was not afraid to enter students' space, and she spent time with each student at his or her desk. Maya explained that this "closeness" is intentional:

So if you go up to them and you see what they're doing . . that's when they're like, "Oh, I don't get it," or something like that... If I just stand at the board all day they'll never . . . some kids will never open up. . . . So that's why I kind of feel it's important to go to every single one whether they know how to do it or not ... I think it is a good teaching practice that is a very strong quality of a warm demander. (MI1)

Maya's goals were transparent: she enacted the warm demander stance so that her students would perceive that she is "putting forth the effort towards them" (MI1) in ways that keep them academically focused and psychologically comfortable and safe. In practice, Maya worked to get to know students by having conversations with them about their extracurricular activities, their families, and their interests. She did this to gain deeper insights and understandings about her students, thus strengthening the emotional bond between them. In explaining this, she commented:

I guess all teachers get to know kids at the beginning of the year, [with] "about me" sort of things, but it goes beyond that ... just holding conversations with them ... it comes very often in the classroom you get the opportunity to just get to know another This is an Author's Original Manuscript. The final publication is available at Springer via http://dx.doi.org/10.1007/s11256-016-0350-4 


\section{ELEMENTARY PRESERVICE TEACHERS AS WARM DEMANDERS}

personality ... I do that all the time with them ... I like to know their perspective, so it lets me see how they think. (MI1)

In this way, she believed that she was developing an authentic connection with students, extending strategies often used at the beginning of the school year to get to know students. While Maya excelled in her ability to connect with students by weaving conversation into her teaching, this also presented a challenge as there were times when she had difficulty maintaining an academic focus and needed to reel in talk that steered away from academic content. Maya recalled times when she had to negotiate with students about the direction of classroom conversation and emphasized that while she embraced the belief that developing personal relationships with students was an important aspect of warm demanding, she was still learning how to decide when the conversation had gone off topic and what to do when that happened.

Maya's enactment of the warm demander as caregiver extended outside the walls of the classroom to connect with students on a more personal level. Maya valued the opportunities that extracurricular activities provided to develop relationships with students' families. Like Katelyn, Maya attended the morning worship service at a predominately African American church and her school's fall festival. In online discussions, she emphasized that these experiences strengthened her relationship with students by helping her gain cultural knowledge about their African American heritage. In an online discussion post, she described the festival as important because, "being able to see your students interact with family and friends outside of a normal school day really helps to get to know their personality and their true interests" (MDF111609), and the church service as an "eye-opening" experience where she learned "how important family and community are to the people of the African American culture" (MDF100809). More importantly, Maya took away key pedagogical insights:

This is an Author's Original Manuscript. The final publication is available at Springer via http://dx.doi.org/10.1007/s11256-016-0350-4 


\section{ELEMENTARY PRESERVICE TEACHERS AS WARM DEMANDERS}

Taking part in whole group lessons with the call-and-response format would allow students to be themselves ... in an educational [environment]. Also, incorporating movement and music ... will engage students as it did at the church. Songs can be modified to integrate different lessons and/or skills that students can make up on their own or use from other sources. Making the classroom an overall comfortable and warm environment that embraces everyone's different personalities and strengths will bring the environment created by the church into the classroom. (MDF100809)

After observing the cultural practices at the church, Maya began to experiment with some of these ideas in the classroom. She shared her experience using the call-and-response strategy after attending the church service:

After going to the church service, I realized how important it would be to incorporate choral responses in the classroom. I have tried to incorporate more opportunities for students to give choral responses during the day. I usually use choral responses when reviewing old material or introducing a lesson. (MDF100609)

\section{Maya: The Warm Demander as Authority Figure}

Maya's embracing of the warm demander as an authority figure is expressed through her belief that insistence is essential in order to provide a classroom environment where students can learn. According to Maya, without insistence, students won't "get the message that's being sent", students will "lose trust in [the teacher]," and the teacher can't create a "fair classroom environment" (MI2). In commenting about consistent insistence, Maya shared, "I think consistency in all factors helps kids get into a routine of their own as well as it helps classroom management. I think it improves their learning because they know what's expected of them" (MI2).

This is an Author's Original Manuscript. The final publication is available at Springer via http://dx.doi.org/10.1007/s11256-016-0350-4 


\section{ELEMENTARY PRESERVICE TEACHERS AS WARM DEMANDERS}

Maya's perspective communicates that insistence is student-centered and functions to directly benefit African American learners rather than to simply control behavior. Maya also communicated her understanding of the warm demander as an authority figure through her belief that insistence was a way she demonstrated care for her students. In other words, Maya understood the reciprocal relationship between care and insistence, the two features that together characterize the warm demander stance. She explained,

[Warm demanding is] ... telling student[s] they need to sit down and go back and rethink something, and they know that you want them to try harder-not that you're shooing them away [but] you've built that sort of relationship that they understand. . . They know well maybe they didn't do it right and [the teacher] wants me to do better... [Warm demanding] has an implication that you want them to excel. (MI1)

At times though, she was concerned about her students' perception of her as mean. In her final interview she confided that she sometimes felt bad when she had to reprimand students, but that she knew she had to insist as a way to establish respect, fairness, and consistency. She was at times unsure about how persistent insistence was best conveyed:

I wish I didn't let the little annoying things bother me in the class . . like . . the playing with all the stuff and the talking, the standing. . . I feel like I focus too much on it, but at the same time they need to know. . . . That bothers me because I just feel bad that I have to do it, but I know that I have to; I just don't know if I'm doing it in the right fashion. (MI2)

Maya's concerns were reflective of a novice who fully accepted her role as disciplinarian, yet struggled with striking the balance needed to give students both "comfort and control" (MI1). 


\section{ELEMENTARY PRESERVICE TEACHERS AS WARM DEMANDERS}

To manage this dilemma, Maya tried to place more emphasis on making sure she and her students were connected in ways that made her firm tone convey care.

Maya actualized her belief in insistence through the way she sought to ensure all students were focused and ready to learn. As a warm demander, Maya insisted that students meet high expectations while scaffolding them to meet those expectations. Maya also viewed insistence as directly linked to maintaining a safe and supportive classroom community. In explaining her rationale for allowing students time to focus, she revealed,

If you wait and make sure that everyone's on the same page you probably avoided a lot of ... factors that could slow things down. ... . If you just jump into something and one kid has the book closed and one kid's talking to his friend and you did the lesson ... but not everybody was engaged ... so if they're all ... on the same page, they all know what they're supposed to be doing . . . which is also kind of soothing for them. (MI2)

Similarly, Maya insisted on excellence by attempting to refocus students whenever she observed them disengage. She addressed the behavior immediately and then returned to teaching the lesson. In reflecting on her teaching, Maya commented,

You know, I think a warm demander would definitely stop the lesson [when students disengage], maybe ask kids why is it that they don't know what they're doing and then from there . . . analyze it right away and redo it so that everyone gets it . . it's part of . . making sure that everyone's kind of comfortable in that environment, and I think that when [teachers are] able to do that it helps those kids kind of come back. (MI1) Maya expected her students to be actively in tune with her lessons. This translated into her efforts to keep learners physically and mentally engaged. Rather than give up on students by sending them to time out or to the office when they lost focus, she stopped a lesson and This is an Author's Original Manuscript. The final publication is available at Springer via http://dx.doi.org/10.1007/s11256-016-0350-4 


\section{ELEMENTARY PRESERVICE TEACHERS AS WARM DEMANDERS}

demanded their attention. Furthermore, in her analysis of possible reasons for her students' disengagement, she critically interrogated her own practice instead of blaming her students:

It could also be the teacher's fault that kids aren't sure what they're supposed to be doing. It's probably the way that I'm delivering it because you have to think about it ... it's [easy] to blame them [students] if they don't get it, but if eighty percent of the class doesn't get it . . you might have to re-explain it or reevaluate the situation. (MI1)

Her reflections about student engagement provided additional insight into the concept of warm demanding. She realized that a warm demander is also someone who "fully engages students" and is the kind of teacher who "is innovative and has to be impromptu because the course of your lesson can change in a minute" (MI2). These comments were reflective of a PST who was beginning to accept responsibility for student learning. Midway through the internship, she shared with classmates her belief that "it is the teacher who sets the environment for wanting to learn" (MDF102109). Critical self-reflection and accountability, as well as insistence are important attributes that were evident in Maya's understanding of warm demanding.

Maya's understanding of warm demanding included several features that characterize the warm demander stance when working with African American students. Emotional connectedness established through positive, fluid relationships; emphasis on classroom community; consistent insistence; and scaffolding students to success are aspects that Maya embraced and enacted. Though she was not at the point of orchestrating all of these elements in her practice, the data revealed that Maya was developing the conceptual and practical tools to help her second graders achieve educational success.

\section{Discussion and Implications}

This is an Author's Original Manuscript. The final publication is available at Springer via http://dx.doi.org/10.1007/s11256-016-0350-4 


\section{ELEMENTARY PRESERVICE TEACHERS AS WARM DEMANDERS}

The case studies illuminate the experiences of two PSTs who were actively working to become warm demanders for their African American students. Katelyn and Maya shared similar commitments related to the key features of warm demanding yet enacted the stance somewhat differently.

The cases show that both PSTs were committed to developing relationships with students, cultivating a culture of achievement, and insisting that students meet high expectations. The variations in their warm demanding revealed that there are different ways teachers can enact it. Katelyn expressed her care for students by learning about their families and culture, and deliberately using this knowledge to plan engaging and relevant lessons to ensure their success. In contrast, Maya's expressions of care were manifested in the emotional bond she sought to cultivate with them, thereby securing their cooperation and engagement in learning. Both PSTs believed that their persistent insistence, or authoritative posture, was an expression of their care. Katelyn's enactment of authority was expressed in her instructional urgency while Maya's was enacted in her efforts to create a safe and supportive environment in which all students could learn. Despite their differences, both PSTs fretted about being perceived by their students as "mean." Their anxiety is much more revealing about their powerful socialization into the culture of "niceness" (Castagno, 2014) than about the actual content and delivery of their communications with students. Still, rattling the chains of a niceness that limits the thinking and agency of so many PSTs is an important goal for teacher educators who wish to cultivate warm demanding in a predominantly White and middle class future teaching corps (Denti \& Whang, 2013). It would be a great shame to find teachers who avoid warm demanding because they perceive that it violates their narrow view of nice behavior. 


\section{ELEMENTARY PRESERVICE TEACHERS AS WARM DEMANDERS}

Katelyn and Maya's concerted enactment of warm demanding as a comprehensive stance of care and authority highlights the potential of teacher education courses, field experiences, and programs to facilitate the development of teacher capacity to teach African American students well. While programs have made progress in this area, few have sought to comprehensively restructure coursework and curriculum to help PSTs better meet the needs of African American children (Ladson-Billings, 2000; Nieto \& McDonough, 2011; Sleeter, 2012). We are not suggesting that PSTs need a separate preparation exclusively for African American children. However, we do argue that approaches to teacher preparation must acutely consider the needs of African American learners, and that teacher educators can create learning experiences designed for this purpose.

In our study, Katelyn and Maya were part of an internship experience focused on helping them develop the capacity to engage all students in learning by recognizing the vital role culture plays in the educational process. Katelyn and Maya were afforded opportunities to develop African American cultural knowledge, implement culturally congruent instructional frameworks, and critically evaluate and reflect on their own perspectives and identities. They were guided by an experienced professor with an in-depth understanding of teaching in urban contexts. This instructor served as a guide to help Katelyn and Maya interpret their observations and experiences. Such practice was recently documented by the NCATE Blue Ribbon Panel (2010) as critical to the success of PST field experiences, and has been extensively documented as effective by researchers (Milner, 2009; Sleeter, 2008). With the scaffolding provided by the course, Katelyn and Maya were able to see themselves as capable of successfully teaching African American children. Such a vision represents a paradigmatic shift in the way teachers, particularly beginning teachers, tend to think about their own ability to teach African American This is an Author's Original Manuscript. The final publication is available at Springer via http://dx.doi.org/10.1007/s11256-016-0350-4 


\section{ELEMENTARY PRESERVICE TEACHERS AS WARM DEMANDERS}

students (Milner, 2009). Fitchett, Starker, and Salyers (2012) state that PSTs "have to feel efficacious in their ability to implement culturally responsive or warm demanding practices in the context of their own classrooms" if they are to successfully enact this pedagogy. However, many PSTs feel unprepared and unable to teach African American students despite graduating from a teacher preparation program (Siwatu, 2011). Our study suggests that teacher educators can structure coursework and learning experiences that can help PSTs develop confidence and agency in teaching African American youth.

Simultaneously, our investigation of PSTs as warm demanders offers us much to consider regarding our own conceptions of warm demanding. Indeed, our work reveals just as much about our own knowledge related to warm demanding as it does about our PSTs. Through Maya and Katelyn's emerging perspectives about warm demanding, we found that there remains a great deal for us to learn about the complex manner in which many teachers promote educational excellence for children of African descent in American schools.

While the theoretical premises of warm demanding were implicitly embedded in the design and curriculum of the course, some of these premises were not explicitly included as components of course content, assignments, or experiences. A more nuanced view of the warm demander, as grounded in political clarity and committed to community uplift was not strongly conveyed in the course, and, therefore, it is not surprising that these goals are absent in interviews and online discussion data. That is, the two PSTs did not connect the features of warm demanding to the social, historical, or political experiences and realities of African Americans, which may have narrowed their conceptions of warm demanding and reduced the power of their enactment (Author, 2013). Preparing PSTs for teaching African American students demands a pedagogy that takes direction from a distinctive sociocultural consciousness. This sociocultural This is an Author's Original Manuscript. The final publication is available at Springer via http://dx.doi.org/10.1007/s11256-016-0350-4 


\section{ELEMENTARY PRESERVICE TEACHERS AS WARM DEMANDERS}

consciousness includes recognition of racial injustice and a commitment to dismantling social inequities on the behalf of African American communities (Author, 2013). Although the course explicitly addressed some facets of African American cultural knowledge (i.e., exposing PSTs to African American cultural practices), understanding and critiquing the systemic inequities African Americans face are critical to the successful enactment of warm demanding (e.g., making visible the influence of racism on schooling experiences). Such an omission may have led Maya and Katelyn to develop a race neutral understanding of warm demanding, which could limit the power of their pedagogical enactments (Author, 2013). This insight underscores Ladson-Billings' (2000) argument:

To prepare teachers to be successful with African American students, teacher educators must help prospective teachers recognize the ways that race and racism structure the everyday experiences of all Americans ... teachers must understand how race and racism negatively impact African American students and their ability to successfully negotiate schools and classrooms. (p. 211)

Examining Maya and Katelyn's conceptions and instructional practices related to warm demanding provided us with new insights about the importance of contextualizing warm demanding for African American students within an African American political, cultural and historical milieu (Author, 2013). Doing so in our work might lead PSTs to make broader, more relevant connections between culture and educational achievement. It may also help PSTs to redefine their professional identities and expand their professional roles in order to serve African American students well.

This is an Author's Original Manuscript. The final publication is available at Springer via http://dx.doi.org/10.1007/s11256-016-0350-4 


\section{ELEMENTARY PRESERVICE TEACHERS AS WARM DEMANDERS}

\section{References}

Allen, A. \& Butler, L. (1996). The effects of music and movement opportunity on the analogical reasoning performance of African American and White school children. Journal of Black Psychology, 22(3), 316-328.

Authors (2007).

Authors (2008).

Author (2013).

Authors (2013).

Bettleheim, B. (1965). Teaching the disadvantaged. National Education Association Journal, 54, 8-12.

Bonner, E. P., \& Adams, T. L. (2012). Culturally responsive teaching in the context of mathematics: a grounded theory case study. Journal of Mathematics Teacher Education, 15(1), 25-38.

Boykin, A. W. (1994). Afrocultural expressions and its implications for schooling. In E. R. Hollins, J. E. King, \& W. C. Hayman (Eds.), Teaching diverse populations: Formulating a knowledge base (pp. 243-256). New York: State University of New York Press.

Boykin, A. W., Tyler, K. M., \& Miller, O. A. (2005). In search of cultural themes and their expressions in the dynamics of classroom life. Urban Education, 40(5), 521-549.

Castagno, A. E. (2014). Educated in whiteness: Good intentions and diversity in schools. Minneapolis and St. Paul, MN: University of Minnesota Press.

Boser, U., Wilhelm, M., \& Hanna, R. (2014). The power of the pygmalion effect: Teacher expectations strongly predict college completion. Retrieved from Center for American Progress

This is an Author's Original Manuscript. The final publication is available at Springer via http://dx.doi.org/10.1007/s11256-016-0350-4 


\section{ELEMENTARY PRESERVICE TEACHERS AS WARM DEMANDERS}

https://www.americanprogress.org/issues/education/report/2014/10/06/96806/the-powerof-the-pygmalion-effect/.

Charney, R. S. (2002). Teaching children to care: Classroom management for ethical and academic growth, K-8. Greenfield, MA: Northeast Foundation for Children.

Corbett, H. D., Wilson, B. L., \& Williams, B. (2002). Effort and excellence in urban classrooms: Expecting, and getting, success with all students. New York: Teachers College Press.

Darling-Hammond, L. (2010). The flat world and education: How America's commitment to equity will determine our future. New York: Teachers College Press.

Delpit, L. (1995). Other people's children: Cultural conflict in the classroom. New York: The New Press.

Denti, L.G. \& Whang, P.A. (2013). Rattling chains: Exploring social justice in education. Rotterdam, The Netherlands: Sense Publishers.

Diamond, J. B., Randolph, A., \& Spillane, J. P. (2004). Teachers' expectations and sense of responsibility for student learning: The importance of race, class and organizational habitus. Anthropology \& Education, 35(1), 75-98.

Gregory, A., Skiba, R. J., \& Noguera, P. A. (2010). The achievement gap and the discipline gap: Two sides of the same coin? Educational Researcher, 39(1), 59-68.

Fitchett, P. G., Starker, T. V., \& Salyers, B. (2012). Examining culturally responsive teaching self-efficacy in a preservice social studies education course. Urban Education, 47(3), 585-611.

Hart, J. E., Cramer, E. D., Harry, B., Klingner, J. K., \& Sturges, K. M. (2010). The continuum of "troubling" to "troubled": Behavior exploratory case studies of African American students in programs for emotional disturbance. Remedial and Special Education, 31(3), This is an Author's Original Manuscript. The final publication is available at Springer via http://dx.doi.org/10.1007/s11256-016-0350-4 
ELEMENTARY PRESERVICE TEACHERS AS WARM DEMANDERS

148-162.

Hatch, J. A. (2002). Doing qualitative research in educational settings. Albany, NY: State University of New York Press.

Heard, S. R., Heard, K., Dirmann, J., Hendry, D., Neill, R., Davis, J. T., Toliver, K., ... Peabody Collection. (2010). “Good morning Miss Toliver.” Pasadena, CA: Foundation for Advancements in Science and Education.

Hilliard, A. (2014). What do we need to know now? In W. Au (Ed.), Rethinking multicultural education: Teaching for racial and cultural justice (pp. 29 -42). Milwaukee, WI: Rethinking Schools.

Hunter, K. Q. (2012). Urban schools, teacher preparation for diversity. In J. A. Banks (Ed.) Encyclopedia of diversity in education (pp. 2274 - 2277). Thousand Oaks, CA: Sage.

Irvine, J. J. \& Fraser, J. W. (1998). Warm demanders: Do national certification standards leave room for the culturally responsive pedagogy of African American teachers? Education Week, 17(35), 56-57.

Kleinfeld, J. (1975). Effective teachers of Eskimo and Indian students. The School Review, 83(2), 301-344.

Ladson-Billings, G. (1994). The dreamkeepers: Successful teachers of African American children. San Francisco: Jossey-Bass.

Ladson-Billings, G. (2000). Fighting for our lives: Preparing teachers to teach African American students. Journal of Teacher Education, 51(3), 206-214.

McCloud, C. (2006). Have you filled a bucket today? Northville, MI: Ferne Press.

Milner, H. R. (2009). Preparing teachers of African American students in urban schools. In

This is an Author's Original Manuscript. The final publication is available at Springer via http://dx.doi.org/10.1007/s11256-016-0350-4 


\section{ELEMENTARY PRESERVICE TEACHERS AS WARM DEMANDERS}

L. C. Tillman (Ed.), The SAGE handbook of African American education (pp. 123-139). Thousand Oaks, CA: SAGE Publications.

Milner, H. R., \& Tenore, F. B. (2010). Classroom management in diverse classrooms. Urban Education, 45(5), 560-603.

Moore, J., Lewis, C. W. (2012). African American students in urban schools: Critical issues and solutions for achievement. New York: Peter Lang.

Moss, F. (2010). The impact of cultural information in building cultural competence of preservice teachers in urban schools. (Unpublished doctoral dissertation). University of Florida, Gainesville, Florida.

National Council for Accreditation of Teacher Education (NCATE) Blue Ribbon Panel. (2010, November). Transforming teacher education through clinical practice: A national strategy to prepare effective teachers. Report of the Blue Ribbon Panel on Clinical Preparation and Partnerships for Improved Student Learning. Retrieved from http://www.ncate.org/LinkClick.aspx?fileticket=zzeiB1OoqPk\%3D\&tabid=715.

Nieto, S. \& McDonough, K. (2011). Placing equity front and center revisited. In A. F. Ball \& C. A. Tyson (Eds.), Studying diversity in teacher education (pp. 363-384). Landham, MD: Rowman \& Littlefield Publishers.

Nobles, W. (1985). Africanity and the Black family: The development of a theoretical model. Oakland, CA: Black Family Institute Publications.

Ornstein, A., \& Viaro, P. (Eds.). (1968). How to teach disadvantaged youth. New York: David McKay.

Palmer, C. J. (2010). The role of teacher expectation on disproportionality of African American

This is an Author's Original Manuscript. The final publication is available at Springer via http://dx.doi.org/10.1007/s11256-016-0350-4 


\section{ELEMENTARY PRESERVICE TEACHERS AS WARM DEMANDERS}

males in special education in middle schools in Richmond county school system.

(Unpublished doctoral dissertation). Georgia Southern University, GA.

Payne, R.K. (2005). A framework for understanding poverty $\left(4^{\text {th }}\right.$ ed.). Highlands, TX: Aha! Process, Inc.

Potter, J. (1996). Representing reality: Discourse, rhetoric and social construction. Sage Publishers.

Siwatu, K. O. (2011). Preservice teachers' sense of preparedness and self-efficacy to teach in America's urban and suburban schools: Does context matter? Teaching and Teacher Education, 27(2), 357-365.

Sleeter, C. E. (2008). Preparing white teachers for diverse students. In M. Cochran-Smith, S. Feiman-Nemser, J. D. McIntyre, \& K. E. Demers (Eds.), Handbook of Research on teacher education: Enduring questions in changing contexts (pp. 559-582). New York: Routledge.

Sleeter, C. E. (2012). Confronting the marginalization of culturally responsive pedagogy. Urban Education, 47(3), 562-584.

Smitherman, G. (1977). Talkin and testifyin: The language of Black America. Detroit: Wayne State University Press.

Siddle Walker, V. (1993). Interpersonal caring in the "good" segregated schooling of African American children: Evidence from the case of Caswell County Training School. The Urban Review, 25(1), 63-77.

Spradley, J. P. (1980). Participant observation. New York: Holt, Rinehart, and Winston. 
Sunderman, G.L. \& Kim, J. (2005). Teacher quality: Equalizing educational opportunities and outcomes. Cambridge, MA: The Civil Rights Project at Harvard University.

Tillman, L. C. (2002). Culturally sensitive research approaches: An African American perspective. Educational Researcher, 31(9), 3-12.

Ware, F. (2006). Warm demander pedagogy: Culturally responsive teaching that supports a culture of achievement for African American students. Urban Education, 41(4), 427-456.

This is an Author's Original Manuscript. The final publication is available at Springer via http://dx.doi.org/10.1007/s11256-016-0350-4 